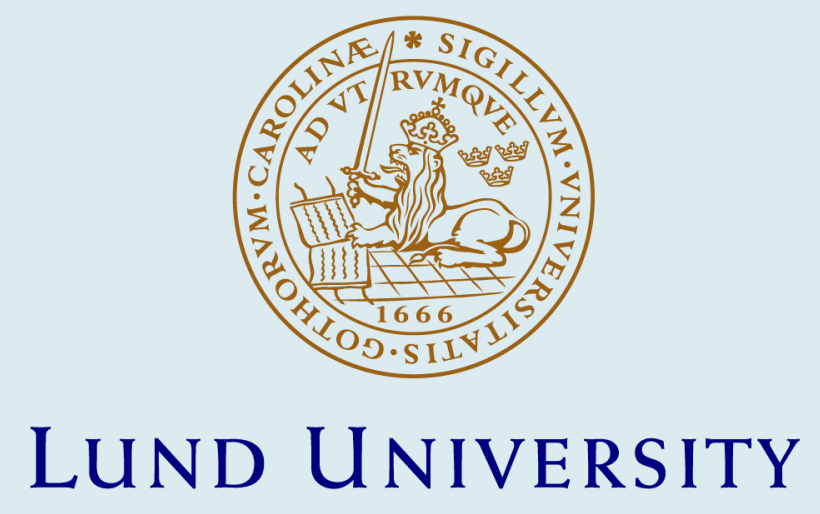

\title{
Optical Tissue Diagnostics: Fluorescence and Transillumination Imaging
}

\section{Svanberg, Sune}

Published in:

Optics and Photonics News

DOI:

10.1364/OPN.3.10.000031

1992

Link to publication

Citation for published version (APA):

Svanberg, S. (1992). Optical Tissue Diagnostics: Fluorescence and Transillumination Imaging. Optics and Photonics News, 3(10), 31-34. https://doi.org/10.1364/OPN.3.10.000031

\section{Total number of authors:}

1

\section{General rights}

Unless other specific re-use rights are stated the following general rights apply:

Copyright and moral rights for the publications made accessible in the public portal are retained by the authors and/or other copyright owners and it is a condition of accessing publications that users recognise and abide by the legal requirements associated with these rights.

- Users may download and print one copy of any publication from the public portal for the purpose of private study or research.

- You may not further distribute the material or use it for any profit-making activity or commercial gain

- You may freely distribute the URL identifying the publication in the public portal

Read more about Creative commons licenses: https://creativecommons.org/licenses/

Take down policy

If you believe that this document breaches copyright please contact us providing details, and we will remove

access to the work immediately and investigate your claim. 
Optical Tissue Diagnostics: Fluorescence and Transillumination Imaging

Sune Svanberg

Department of Physics, Lund Institute of Technology, P.O. Box 118, S-221 00 Lund, Sweden

Invited paper for

Optics and Photonics News

December 1991 
photonic, $27 \mathrm{dec}$

\title{
Optical Tissue Diagnostics: Fluorescence and Transillumination Imaging
}

\author{
Sune Svanberg
}

Department of Physics, Lund Institute of Technology,

P.O. Box 118, S-221 00 Lund, Sweden

\begin{abstract}
Electro-optical and spectroscopic techniques are being developed to extend the capability of the human eye in optical tissue diagnosis. By using laser-induced fluorescence, malignant tumors can be detected employing specific spectral signatures of native chromophores or injected tumor-seeking agents. In a similar way, fluorescence can be utilized for making transluminal identification of atherosclerotic plaque to guide a fiber-optic laser ablation system. Tissue optical transillumination has until recently been hampered by heavy multiple-scattering blurring the images. By using time-gated techniques the influence of the scattering can be largely reduced giving promise for an efficient mammographic method using non-ionizing radiation.
\end{abstract}

\section{Introduction}

Optical tissue diagnosis through the experienced doctor's eye has long been a prime method in medical examinations. Through the development of endoscopic techniques it has also become possible to gain optical access to many inner organ, such as the lungs, the urinary bladder, the gastro-intestinal tract and larger vessels. Through the biopsy channel of such fiber-optic instruments it is also possible to collect specimen for histopatological investigation and to perform treatment procedures, e.g. employing laser radiation. An extension of the optical diagnosis using reflected light is provided by the fluorescence phenomenon. Laser-induced fluorescence (LIF) can be used for identifying malignant tumors through specific spectroscopic features of endogenous tissue chromophores and tumor-seeking artificial agents, such as porphyrins. This can help localize early cancer for treatment before the disease becomes more widespread and more difficult to manage.

Transluminal angioplasty for treatment of cardiovascular disease is an attractive alternative to more dramatic procedures such as open-heart by-pass operations. Laser ablation can be expected to become more safe when performed with spectroscopic guidance. Fluorescence diagnostics mainly pertains to thin superficial layers because of the limited optical penetration in tissue. Optical transillumination using red or near IR radiation has diagnostic potential, but has been hampered by the heavy multiple scattering in tissue. Image blurring can be reduced by using time-gated techniques. Mammographic methods without using ionizing radiation are under development.

In the present paper a brief review of some of these new optical tissue diagnostic techiques is made. Many interdiciplinary groups, where physicians and physicists work together have been formed leading to a rapid advancement of the field. Many aspects of optical techniques in medicine have been covered in a recent special issue of IEEE J. Quant. Electronics ${ }^{1}$.

There also our own work in the field of cancer, atherosclerosis and transillumination is presented ${ }^{2}$. 


\section{Malignant tumor diagnostics}

It has been known since long that certain agents are selectively retained in tumor tissue. Tumor localization of sensitizing molecules can be used for a double purpose: for tumor localization using LIF and for tumor treatment through photodynamic therapy (PDT). Presently, the agent Photofrin, which is a hematoporphyrin derivative, is the only one in more widespread exploratory clinical use. An intensive search for new and more optimal sensitizers is going on and agents belonging to the classes of bensoporhyrins, phtalocyanines, chlorines and purpurins are being investigated in animal experiments and in early clinical work. Most aspects of photosensitizers in the management of cancer are treated in a recent book ${ }^{3}$.

For LIF diagnosis a convenient excitation source is a small, sealed-off nitrogen laser (337 $\mathrm{nm})$, either used directly or pumping a dye laser generating radiation at, e.g. $405 \mathrm{~nm}$, which corresponds to the main absorption band of porphyrins. The radiation is transmitted through a quartz fibre, which can be brought through the biopsy channel of an endoscope to be placed in contact with the tissue to be diagnosed. LIF is collected by the same fibre and is brought back to the entrance slit of a small monochromator equipped with an intensified diode array detector, capturing the full spectrum in each laser shot. Using such or similar equipment we and other groups have performed extensive spectral studies for diagnostic purposes. Using Photofrin as a sensitizer, tumors show up with an increased fluorescence emission in the red spectral region (peaks at 630 and $690 \mathrm{~nm}$ ). At the same time the blue-green fluorescence due to the tissue chromophores is observed to be reduced, a phenomenon that seems to be connected to the balance between strongly fluorescent $\mathrm{NADH}$ and weakly fluorescent $\mathrm{NAD}^{+}$in tumour tissue 2,4 . By dividing the (background-free) red intensity increase by the blue intensity decrease an enhanced demarcation between tumor and healthy tissue is obtained at the same time as the use of a dimensionless quantity yields immunity to geometrical variations as well as to fluctuations in the source and detector efficiencies.

An extension from point monitoring, as described above, to imaging can be achieved by using 2-D intensified ccd detectors. In Lund we have developed a multi-color fluorescence imaging technique employing special optics allowing for simultaneous spectral registration in up to 4 isolated fluorescence bands on the same ccd detector. An application of this system is shown in Fig. 1, where LIF from a rat experimental tumor is shown under nitrogen laser excitation ${ }^{\text {. }}$. Characteristic spectra obtained with a point monitor as described above are included. The spatially resolved intensities in bands around 630, 600 and $470 \mathrm{~nm}$ are recorded and a new enhanced contrast image is calculated, pixel by pixel, from the three individual images. Equipment operating on this principle is now being adopted for clinical use in connection with endoscopes.

Most sensitizers including Photofrin has as a side effect an accumulation of the agent also in the skin calling for the patients to out of bright daylight for a period of about 4 weeks. Because of this it is important to be able to reduce the injected dose below the value for therapy (2 $\mathrm{mg} / \mathrm{kg}$ bodyweight) if LIF diagnosis is the only purpose of the injection. This is possible as recently demonstrated in clinical lung and bladder applications.

Instead of administering the drug intravenously, topical application of the drug on superficial tumors has been successfully used for treatment in the ${ }_{8}$ case of the small porphyrin precursor molecule $\delta$-aminolevulinic acid (ALA) ${ }^{8}$. We have just esfablished that ALA is a very efficient fluorescent marker for cancer tumors. Endogenous porhyrins have also been found to accumulate in tumors, making tumor detection in the gastro-intestinal tract possible without drug injection in some cases ${ }^{10}$. 


\section{Plaque diagnostics}

Cardiovascular disease is the primary cause of death in Western countries. Coronary by-pass operation is presently a common and safe procedure to assure an adequate blood supply to the heart muscle. Still the operation is quite traumatic for the patient with a considerable hospitalization time and associated high costs. Different transluminal angioplastic procedures are being developed as alternatives to major surgery in certain cases. Laser angioplasty has a potential for effective vessel treatment. In order to make such a procedure safe a guidance system must be provided to avoid vessel dissection and perforation. Several groups have been active in developing LIF as a tool for such guidance. A schematic diagram of a laser angioplasty system with spectroscopic guidance is shown in Fig. 2 incorporating i small UV laser for LIF generation and a spectral unit to decide whether a high energy treatment laser shot can be fired safely or not.

The fluorescence signatures have been shown in vitro to be sufficiently different to allow a differentiation between normal and diseased tissue. In clinical work the presence of blood leading to strong alterations in the fluorescence spectrum through reabsorption by hemoglobine is a complication. We have shown that such difficulties can be circumvented by choosing wavelength pairs with equal blood reabsorption and forming the ratio. Immunity to blood can also be rendered by working in the time domain focusing on different fluorescence decay times for different tissue types ${ }^{2}$. Examples of signals for plaque and normal vessel wall are shown in Fig. 2 in the spectral and in the temporal domain.

For achieving a laser-ablated new lumen of sufficient diameter many groups are now working on the development of new multi-fiber catheters. Such catheters and spectroscopic guidance are hoped to reduce the restenosis rate, which is now high for all transluminal procedures.

\section{Tissue transillumination}

Tissue absorption is comparatively low in the red and near IR spectral region between around $600 \mathrm{~nm}$, where blood absorption falls off strongly and $1.3 \mu \mathrm{m}$, where water absorption increases rapidly. Diagnostic breast transillumination has been demonstrated since some time, but the value has been limited because of strong image blurring due to heavy multiple scattering in human tissue. In order to make this technique useful a number of techniques for ${ }_{11}$ suppressing the scattered light are now being developed by several group ${ }^{11}$. We demonstrated the first enhanced imaging through living human tissue (a hand) by a time-gated technique ${ }^{2}$. A synchronously pumped and cavity dumped picosecond dye laser was used to transmit 6 ps pulses through the tissue. Single photons were detected with a microchannel plate detector connected to delayed-coincidence electronics. By using only the early arriving photons for the image formation it is possible to suppress the main part of the scattering. In this way the bones of the hand could be seen forming "shadows".

In Fig. 3 the result of a scan through a newly resected breast specimen with a cancer tumor (ductal carcinoma) can be seen ${ }^{13}$. In the scan the tumor is revealed through an increased signal in the time-gated recording, whereas it is not detectable using the total light. By computer simulations and also model experiments in which the absorption and scattering properties of a tissue phantom could be varied freely it is possible to understand the positive time-gated signal. For a sample of the given thickness $(16 \mathrm{~mm})$ there are extremely few non-scattered photons. The detection temporal window (120 ps long) is set to accept some early 
arriving photons giving rise to a certain background intensity in normal tissue. In the tumor the absorption is basically the same and thus it does not show up in the time-integrated scan. However, the scattering is less in the tumor resulting in more photons moving into the set detection window resulting in an increasing recorded intensity. Recently, we have obtained similar results using a pulsed diode laser operating at $815 \mathrm{~nm}$ and a pulse length of $30 \mathrm{ps}$. Using computer-controlled $\mathrm{X}-\mathrm{Y}$ translational stages for scanning a transmitter and a receiver fiber in synchronism bridging a measurement volume defined by parallel glass plates first breast tumor images have been obtained.

Using higher-power picosecond lasers together with optically pumped Kerr shutters, streak cameras, or gated Raman amplifiers, different groups are developing similar, time-gated techniques. In an alternative approach phase shifts and modulation-depth losses are detected after passage of modulated laser light through the scattering medium. Other techniques rely on the presence of an unscattered component of the transmitted light for coherent detection of the signal using heterodyne or light-in-flight holographic techniques.

\section{Discussion}

The future of novel tissue diagnostics will depend on the success of the techniques in clinical work and, interconnected with this, on the future availablility of realistic laser and electro-optics equipment. For fluorescence diagnostics, compact solid-state lasers operating in the UV or violet spectral region will be particularly valuable. Frequency-doubled titanium sapphire, LI(S)CAF and diode lasers show great potential. Lowercost image intensifiers would also strongly stimulate a fast development of the field. Red diode lasers with high average power will be extremely useful for conventional thermal applications and for PDT. Higherperformance picosecond diode lasers in conjunction with ultrafast solid-state detectors should make time-gated transillumination very realistic.

The dynamic development of new optical tissue diagnostic techniques will foremost continue to rely on a close interdisciplinary collaboration between physicists and physicians sharing the joy of contributing to the relief of human suffering.

\section{Acknowledgements}

The author gratefully acknowledges a most stimulating collaboration with a large number of collegues and students, as well as support from several Swedish funding agencies.

\section{References}

1. IEEE J. Quant. Electronics QE-26, 1990, 2146-2305, Special issue, Ed. R. Birngruber

2. S. Andersson-Engels, J. Johansson, U. Stenram, K. Svanberg and S. Svanberg, "Malignant tumor and atherosclerotic plaque diagnosis using laser-induced fluorescence", in Ref. 1, pp. 2207-2217

3. T. Dougherthy and B. Henderson, eds., Photodynamic Therapy. Basic Principles and Clinical Aspects (Marcel Dekker, New York 1992) 
4. W. Lohmann, J. Mussman, C. Lohmann and W. Künzel, "Native fluorescence of the cervix uteri as a marker for dysplasia and invasive carcinoma", Eur. J. Obstet. Gynecol. Reprod. Biol. 31, 1989, 249-253

5. S. Andersson-Engels, R. Berg, J. Johansson, O. Jarlman, K. Svanberg, S. Svanberg and S. Montán, Proc. CLEO'91, OSA Technical Digest Series Vol. 10, p. 294

6. S. Lam, B. Palcic, D. McLean, J. Hung, M. Korbelik and A.E. Profio, "Detection of early lung cancer using low dose Photofrin II", Chest 97, 1990, 333-337

7. L. Baert, R. Berg, M.A. D'Hallewin, J. Johansson, K. Svanberg and S. Svanberg, "Detection of superficial bladder cancer utilizing laserinduced fluorescence and low-dose haematoporphyrin derivative", Submitted to J. Urology.

8. J.C. Kennedy, R.H. Pottier and D.C. Pross, "Photodynamic therapy with endogenous protoprophyrin IX: Basic principles and present clinical experience", J. Photochem. Photobiol. B 6, 1990, 143-148

9. R. Berg, J. Johansson, K. Svanberg and S. Svanberg, "Fluorescence diagnostics of cancer using $\delta$-aminolevulinic acid", Unpublished.

10. Y. Yang, Y. Ye, F. Li, Y. Li, B. Ma, "Characteristic autofluorescence for cancer diagnosis and its origin", Lasers Surg. Med. 7, 1987,528532

11. See, e.g. CLEO`91 Technical Digest, pp. 102-104, 294-297 for references.

12. S. Andersson-Engels, R. Berg, O. Jarlman, and S. Svanberg, "Timeresolved transillumination for medical diagnostics", Opt. Lett. 15, 1990, 1179-1181

13. R. Berg, S. Andersson-Engels, O. Jarlman and S. Svanberg, "Timeresolved transillumination for medical diagnostics", SPIE 1431, 1991, 110-119

\section{Figure Captions}

Fig. 1. Fluorescence spectra from tumor and adjacent normal muscle tissue of a rat, injected with Photofrin. The image is calculated, pixel by pixel using the function (A - const $x$ D)/B, from images in spectral bands recording the fluorescence intensities $A, B$ and $D$. Areas with the highest function values are shown bright, areas with intermediate values gray and normal areas black.

Fig. 2. Schematic diagram of a laser angioplasty system with spectroscopic guidance. Typical fluorescence spectra for plaque and normal vessel wall are shown as well as a registration of the ratio of "late" and "early" fluorescence light in a time-resolved recording at several vessel wall locations.

Fig. 3. Recording of transmitted intensity in a scan across a human breast specimen with a tumor. The tumor only appears in a time-gating recording, showing the early arriving light only. 

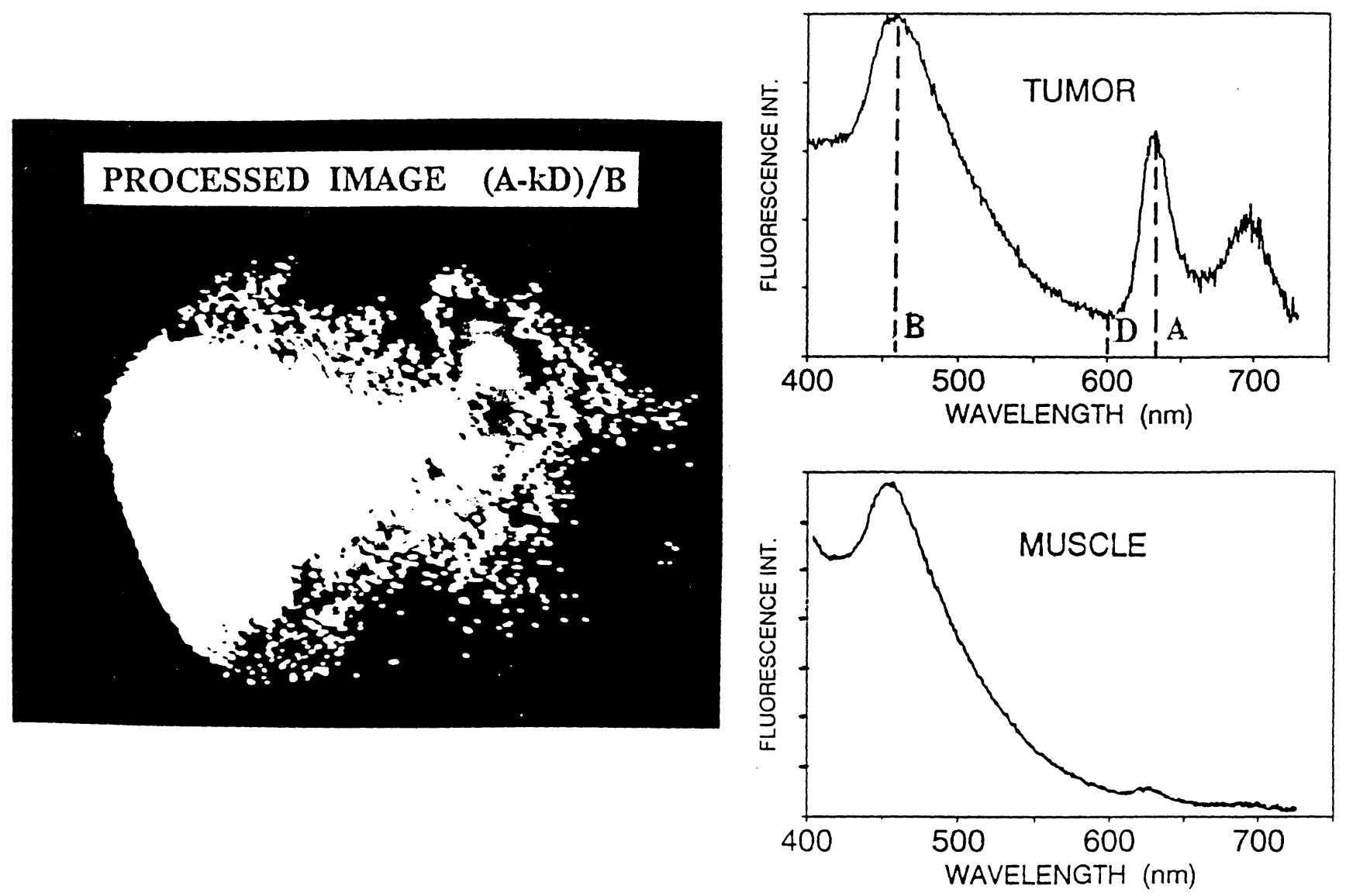

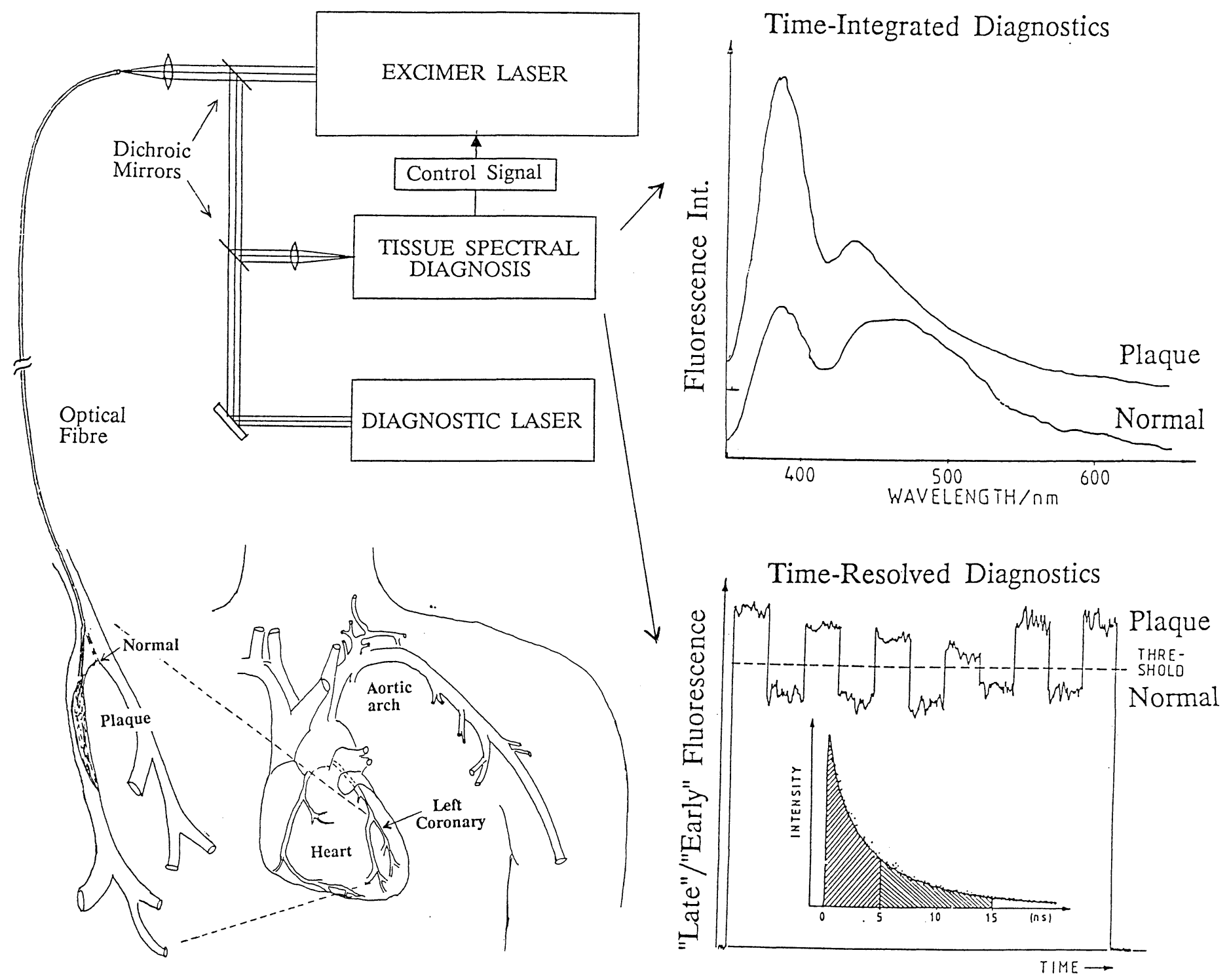


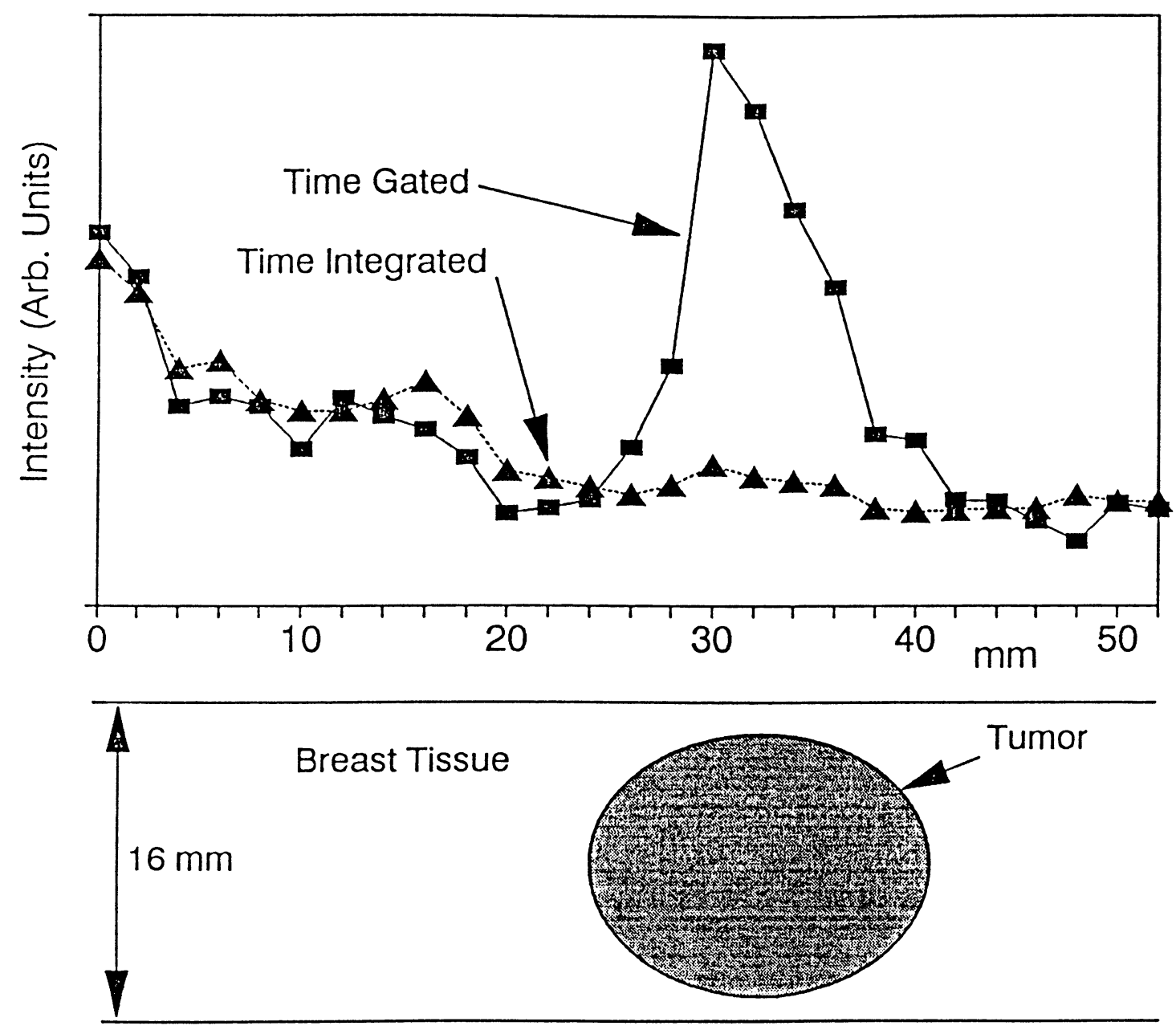

Fig. 3 